\title{
LetI CI A BASso MONTEVerde: La unidad de la diferencia: acerca del acontecimiento en la obra de Heidegger, Buenos Aires: Editorial Biblos, 2017
}

\author{
Luciano Mascaró \\ Universidad de Buenos Aires \\ Icnmascaro@hotmail.com
}

La unidad de la diferencia se propone un objetivo circunscripto, pero no por ello poco ambicioso, sino todo lo contrario: ofrecer una fundamentación que sostenga la idea de una continuidad en la obra de Heidegger. A pesar de la amplitud de la tarea, la obra se dirige a su objetivo sin rodeos, por medio de un plan ordenado que requiere de una serie reflexiones previas que desembocan en una lectura renovada de la trascendencia, el a priori, la diferencia ontológica y la conflictividad o tensión (que se detecta tanto en el Dasein como en el Ereignis).

La autora retoma la lectura de Von Hermann al respecto, y se embarca en un trabajo de justificación de su posición; según Leticia Basso, existe una continuidad en la obra de Heidegger desde las lecciones tempranas de Friburgo hasta los escritos más tardíos. Ahora bien, a diferencia de las aproximaciones más usuales a esta temática, el libro aporta un recorrido novedoso que, en lugar de preguntarse por la reformulación de una cierta temática puntual a lo largo de los años, busca una clave de lectura integral. Se vuelve, pues, necesario establecer un tópico central que atraviesa toda la obra de Heidegger: para la autora este tópico es la diferencia ontológica. Según su lectura, la obra de Heidegger constituye una extensa investigación, desde diversas perspectivas, acerca de la distinción ser-ente.

Para llevar a cabo el objetivo de demostrar la continuidad de la obra de Heidegger, se plantean a continuación una serie de núcleos significativos adicionales que serán rastreados a través del pensamiento de Heidegger, estos núcleos, tal 
como se muestra en el desarrollo del libro, resonarán a lo largo del período analizado (1919-1939) De este modo, la autora se embarca en la difícil tarea de mostrar reduplicaciones, relaciones dialécticas, conflictos y contra-balanceos, que aparecen en todos los períodos, aunque inspeccionados por Heidegger desde perspectivas variantes. Esta variación de perspectivas coincide con el sentido de la Kehre que la autora explicita: el paso del pensamiento del Dasein al pensamiento del ser sin el ente.

Una vez que se ha determinado un tópico central, se buscan una serie de conceptos fundamentales que operarán como clave de lectura de los paralelismos entre los textos tempranos y tardíos. La primera de estas propuestas es la siguiente: El Ereignis tiene una estructura conflictiva (donación-sustracción), que se reduplica en una estructura dual del Dasein (propiedad-impropiedad). Para justificar la dualidad de la estructura del Dasein la autora realiza la que tal vez sea la más audaz tarea del libro (y, a mi juicio, la tarea más necesaria en el ámbito filosófico de la fenomenología hermenéutica): la recuperación del sentido de contenido del a priori, que desemboca en la configuración de la vivencia. Según esta exposición, el planteo trascendental de Ser y tiempo, y, sobre todo, sus interpretaciones posteriores, han priorizado el sentido formal del a priori, es decir, la actividad del Dasein que configura el sentido de lo donado. En la renovada (pero al mismo tiempo, sensata y anti-dogmática) lectura de la autora, existe una fase en la cual el Dasein es pasivo en la recepción del contenido de lo que viene a la presencia, y se pliega a este aparecer para luego, modalizarlo por medio de la dimensión siempre histórica de la comprensión. A este aspecto activo-pasivo de los mecanismos de "lo previo" del comprender la autora lo denomina la "dualidad del a priori":

\footnotetext{
la estructura de la vivencia se va delineando gracias a la influencia de aquello que se dona en una instancia previa a su configuración modal; eso previo refiere al sentido de contenido que de forma pasiva el dasein recibe, y que potencialmente contiene todas las posibilidades a concretarse a través de la articulación y la realización fácticas" (Basso, 2017:258)
}

La tensión entre sentido formal y sentido de contenido se reduplica en la tensión propiedad-impropiedad del Dasein, lo cual, una vez más expresa una conflictividad interna a la existencia, que arraiga en la diferencia ontológica. 
Esta lectura constituye una valiosa y valiente decisión interpretativa, que se volverá condición para la comprensión de las tesis posteriores que se expondrán en el libro. Una vez que se ha establecido, por un lado, una nueva forma de comprender lo trascendental, a saber, no ya como la condición de posibilidad de la experiencia, sino justamente, como la tensión entre lo dado y lo articulado; y, por otro lado, la noción de que el a priori tiene un carácter dual (sentido de contenido y sentido articulado), se puede avanzar al encuentro de estructuras similarmente espejadas en el, así llamado, "segundo período" del pensar de Heidegger.

La segunda parte del libro de Leticia Basso se dedica a explicitar las resonancias de las cuestiones fundamentales de los escritos tempranos (desde la clave de lectura propuesta y sólidamente justificada por la autora, y sin perder de vista el problema de la diferencia como tópico central) en las obras posteriores a la Kehre.

El primer paso para soldar la continuidad es mostrar que el Ereignis, al igual que el Dasein, tiene carácter trascendental (en el sentido no-tradicional ya expresado), puesto que él también constituye una tensión, esta vez, entre entre donación y sustracción del Seyn. En efecto, lo trascendental se mantiene en pie, pero de una manera des-subjetivada. En la conflictividad del Ereignis resuena la dualidad del Dasein. Según la autora, El Ereignis aclara la tensión que genera la diferencia en el Dasein.

Esta reduplicación estructural de fenómenos justifica la continuidad del pensamiento de Heidegger, a saber, la dualidad del Dasein (que es, al mismo tiempo, dualidad del a priori) y el carácter conflictivo del Ereignis son dos modos de análisis y exposición del problema central y aglutinante de la obra de Heidegger: la diferencia ontológica. La distinción entre ambos tratamientos se encuentra en que (tal como lo determina la autointerpretación que Heidegger hace de la Kehre) el primero se realiza desde la perspectiva del Dasein, y el segundo, desde la perspectiva del Seyn.

La autora establece una serie de espejamientos de las estructuras tensionales (o inter-referencias) del primer período en el segundo (si es que esta distinción resulta válida, luego de la lectura de este libro). De este modo se indica:

1) Que la fenomenología hermenéutica por medio de la cual se ejercita la analítica existencial del Dasein posee un correlato en una fenomenología de lo inaparente, en la perspectiva que se ocupa de pensar el Seyn. 
2) La estructura bidimensional del Dasein (dualidad del a priori) resuena en la estructura conflictiva (donación - sustracción) del Ereignis

3) La trascendencia constituye un carácter presente a lo largo de toda la obra de Heidegger, pero, en las obras que se centran en el análisis del Dasein, esta trascendencia aparece como tensión entre lo donado y lo articulado, mientras que en el pensamiento del Ereignis, la trascendencia se presenta como transpropiación.

4) Las dimensiones centrales por medio de las cuales se cristaliza la diferencia son, en las obras de comienzos de siglo XX, la propiedad e impropiedad, que respectivamente, interpretan a la existencia a partir del ente, o del sí mismo. Paralelamente, en la época del pensamiento del Seyn, las dos dimensiones en tensión son la apropiación y expropiación del ser.

La unidad de la diferencia es una obra audaz, y ello desde una serie de puntos de vista.

En primer lugar, se instala de lleno en el centro de una discusión tradicional acerca de la obra de Heidegger (i.e. su continuidad) y la resuelve de una manera no tradicional, trazando relaciones inesperadas pero sólidas entre la estructura del Dasein y del Ereignis. El período abarcado por el estudio es ambicioso (1919 a 1939) pero la autora logra recorrerlo con firmeza, sin abandonar la profundidad de los análisis, mostrando una gran sutileza interpretativa y un sólido manejo de los conceptos fundamentales de cada época y su articulación; una tarea nada sencilla si tenemos en cuenta que el estilo de Heideggery su armazón conceptual se modifica notoriamente a lo largo de los años.

En segundo lugar, la autora propone una novedosa interpretación del a priori que provoca un rescate del sentido de contenido de lo donado. Esta recuperación, a mi juico, llega como una bocanada de aire fresco a las interpretaciones que reducen la totalidad de la vivencia a una suerte de juego semiótico donde la materia ya no tiene nada para decir. La autora nos recuerda, en contra de las interpretaciones que se han vuelto casi dogmáticas, que en una fase inicial, el ente es rector en la configuración del fenómeno, y que el Dasein, al menos en una etapa, cumple un rol pasivo.

Cabe destacar que las renovadas lecturas de la autora no se despliegan sobre aspectos accesorios o satelitales del pensamiento de Heidegger, sino que, tal como ella misma se lo propone, la lectura se inserta justo en la que se presenta como temática central de la obra de Heidegger: la diferencia ontológica. De este 
modo, la autora se diferencia de la mayor parte de las investigaciones que buscan fundamentar la unidad de la obra centrándose en la resonancia de uno u otro concepto particular. Esto significa que todo el estudio de "La unidad de la diferencia" ocurre en el núcleo de una de las áreas más arduas del pensamiento de Heidegger. Leticia Basso logra una firme y contemporánea -además de necesaria - fundamentación de la continuidad de la obra de Heidegger, al tiempo que repiensa una serie de conceptos fundamentales desde una valerosa clave de lectura. Esta obra ofrece una interpretación que no debe ser pasada por alto por ningún interesado en la fenomenología hermenéutica. 